\title{
RFID-enabled real-time manufacturing information tracking infrastructure for extended enterprises
}

\author{
Yingfeng Zhang • Pingyu Jiang • George Huang • \\ Ting Qu • Guanghui Zhou • Jun Hong
}

Received: 23 May 2010 / Accepted: 18 October 2010

(C) The Author(s) 2010. This article is published with open access at Springerlink.com

\begin{abstract}
In extended enterprises, real-time manufacturing information tracking plays an important role and aims to provide the right information to the right person at the right time in the right format to achieve optimal production management among the involved enterprises. However, many enterprises are caused by lack of timely, accurate and consistent manufacturing data. The laggard information transfer flow and the unmatched information transfer method bring extended enterprises much more uncertainty and unknowingness. This paper proposes a RFID-enabled real-time manufacturing information tracking infrastructure (RTMITI) to address the real-time manufacturing data capturing and manufacturing information processing methods for extended enterprises. Following the proposed infrastructure, the traditional manufacturing resources such as employees, machines and materials are equipped with RFID devices (Readers and Tags) to build the real-time data capturing environment. In addition, a series of manufacturing information processing methods are established to calculate and track the real-time manufacturing information such as realtime manufacturing cost, progress, WIP (Work-in-progress) inventory etc. in parts/assemblies/products at machines/shop
\end{abstract}

\section{Y. Zhang ( $\varangle)$}

Key Laboratory of Contemporary Design and Integrated

Manufacturing Technology, Ministry of Education,

Northwestern Polytechnical University, 710072 Xi'an, China

e-mail: zhangyf@nwpu.edu.cn

Y. Zhang $\cdot$ P. Jiang $\cdot$ G. Zhou $\cdot$ J. Hong

State Key Laboratory for Manufacturing Systems Engineering, School of Mechanical Engineering, Xi'an Jiaotong University, 710049 Xi' an, China

e-mail: xjtuzyf@mail.xjtu.edu.cn

G. Huang · T. Qu

Department of Industrial and Manufacturing Systems Engineering,

The University of Hong Kong, Hong Kong, China floors/enterprises/ extended enterprises levels. Finally, a case study is given to demonstrate the developed framework and corresponding methodologies.

Keywords RFID - Real-time manufacturing · Information tracking $\cdot$ Extended enterprises

\section{Introduction}

The concepts of extended enterprises arise partly from the attempts of manufacturers, situated at geographically dispersed locations, to build formal partnerships to gain a competitive advantage (Jagdev 1998). It is now an accepted fact that in the twenty first century, competition will be between value-chains, which efficiently and effectively integrate their competencies and resources to compete in the whole product life cycle, from material procurement and supply management, to production and manufacturing, further to product distribution and customer service, and finally to the recycling and disposal of end-of-life products. Real-time information tracking in extended enterprises is one of the major issues and becoming more and more important because it can speed up the supervisors' response to manufacturing decision making and improve the manufacturing efficiency. Real-time visibility and interoperability have been considered core characteristics of next-generation manufacturing systems (Zhang et al. 2010a; Huang et al. 2007).

As a result, some requisite information is either unavailable or behindhand in current extended enterprises information network. The laggard information transfer flow and the unmatched information transfer method bring extended enterprises much more uncertainty and unknowingness. For example, are there any manufacturing exceptions in involved enterprises, how many products have been produced, how and where raw materials are transformed etc. 
One critical hurdle is a real-time manufacturing information infrastructure imminently required for involved enterprises to achieve real-time and seamless dual-way connectivity and interoperability in extended enterprises, enterprises, shop floors and machines. The following questions are open for investigation:

(1) How to establish an overall real-time manufacturing information tracking infrastructure to support optimal plan and management for extended enterprises?

(2) Which types of manufacturing information should be tracked and how to easily and effectively deploy AutoID devices such as RFID readers and tags for capturing the manufacturing data during production stage?

(3) How to process the distributed real-time manufacturing information to provide useful and meaningful manufacturing information for real-time decision in extended enterprises?

In this research, a RFID-enabled real-time manufacturing information infrastructure is proposed to address above research questions. Rapid development of Auto-ID technologies, such as RFID, facilitates the automatic collection and processing of real-time field data in the manufacturing processes. The presented infrastructure integrates RFID techniques and manufacturing information processing methods to implement real-time visibility and interoperability for extended enterprises. This research aims at providing the right information to the right person at the right time in the right format anywhere in extended enterprises. It contributes to making information flow fluent and the extended enterprise model practical.

The remainder of this paper is organized as follows. After reviewing the related literature in "Literature review", the overall infrastructure of RFID-enabled real-time manufacturing information tracking infrastructure in extended enterprises is proposed in "Overall infrastructure of RTMITI". In "RFID-enabled real-time manufacturing information capturing in shop floor", a configuration model is established to equip traditional manufacturing resources with RFID devices to capture real-time manufacturing data. Real-time manufacturing information tracking models such as manufacturing cost, progress, WIP inventory etc. are designed in "Real-time manufacturing information processing methods for extended enterprises". In order to demonstrate the framework and methods mentioned above, a running example is shown in "Case study". Conclusions are drawn with brief comments in "Conclusion".

\section{Literature review}

Two streams of literature are relevant to this research. They are information sharing and tracking techniques of extended enterprises and real-time manufacturing information capturing.

Information sharing and tracking techniques of extended enterprises

Recently, more and more attentions have been paid to manufacturing information sharing and tracking in extended enterprises. Amours et al. (1999) presents the impact of information sharing between firms of a manufacturing network. Under the concept of enterprise integration, Chen and Jan (2000) proposes an engineering information management methodology. To enable product information sharing for distributed users, Chan and Chung (2002) establishes an enterprise information portal framework. With the development of information technologies, Estrem (2003) regards Web Services will be a key enabling technology to support information integration between enterprises. Rupp and Ristic (2004) proposes a system to support co-operation in complex production networks by enabling companies to determine and exchange supply information with their customers. A product structure trees has been used to represent product information and product information (Zhang et al. 2004) used. A mobile-agent-based system to provide mobile manufacturing information can be seen in Krishnamurthy and Zeid (2004). Iskanius and Alaruikka (2007) focuses on the importance of process integration in the supply chains from the viewpoint of information flow based on Information and Communication Technology (ICT). Sun and Jiang (2007) put forward a manufacturing information sharing and tracking method based on time-dependent instantiated template nets (TITnets). Jiang and Chen (2007) describe an e-service model for capturing and tracking the manufacturing information. Omar and Moramay (2007) describes a formal framework to integrate express models for sharing and exchanging of data in an Extended Enterprise context.

Real-time manufacturing information capturing

Rapid developments in wireless sensors, communication and information network technologies (e.g. radio frequency identification-RFID or Auto-ID, Bluetooth, Wi-Fi, GSM, and infrared) have nurtured the emergence of Wireless Manufacturing (WM) (Huang et al. 2007) as core Advanced Manufacturing Technology (AMT) in next-generation manufacturing systems (NGMS). As early as in early 1990s, Udoka (1992) has discussed the roles of Auto ID as a real-time data capture tool in a computer integrated manufacturing (CIM) environment. Early RFID manufacturing applications have been further promoted in Li et al. (2004). Johnson (2002) presents a RFID application in a car production line. The 
Fig. 1 RFID-enabled RTMITI for extended enterprises

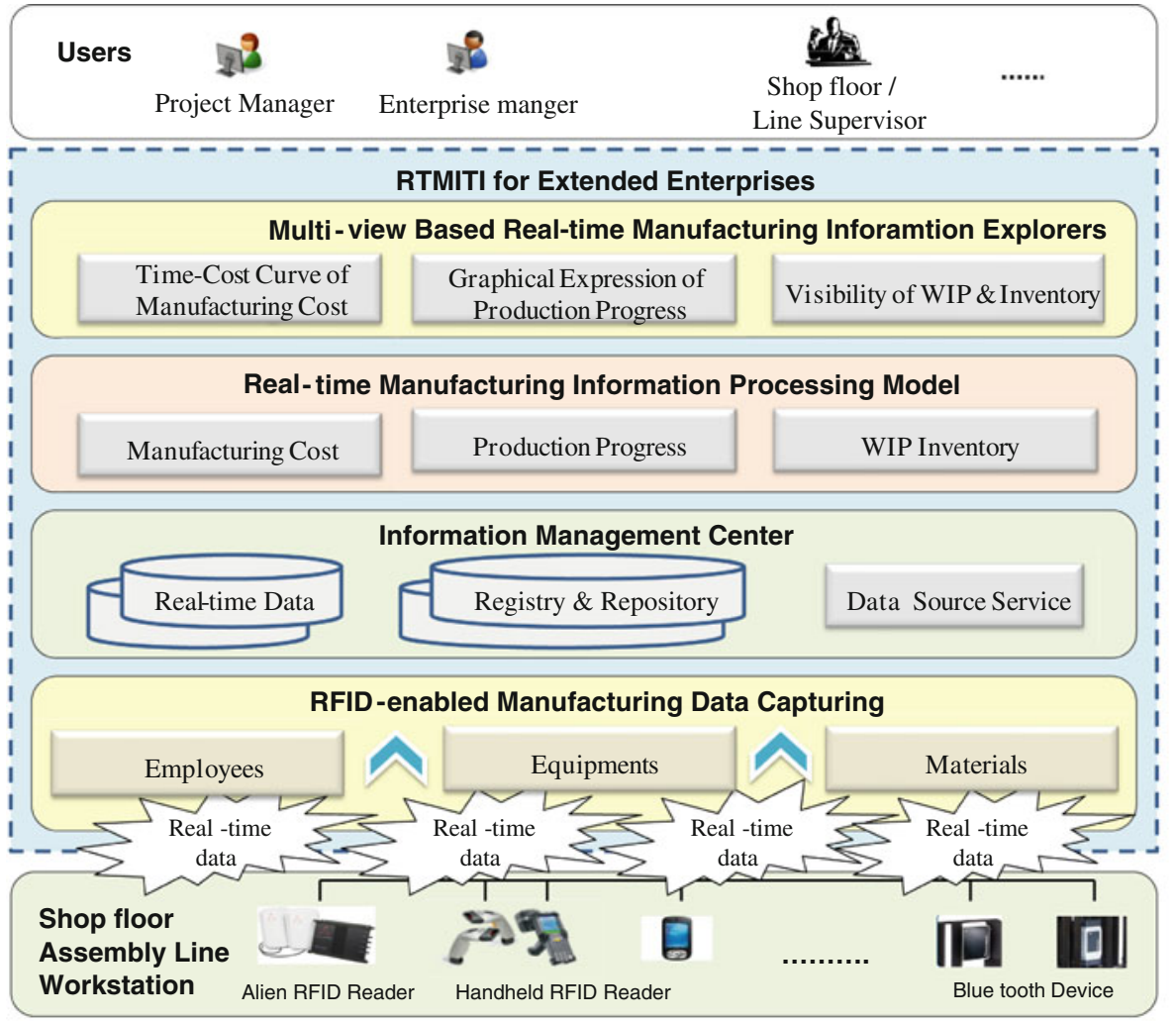

website $^{1}$ also provides a few links to real-life pilot cases. Kohn et al. (2005) is an early piece of precious work in addressing repair-control of manufacturing systems using real-time RFID information. Zhang et al. (2008) describes a smart Kanban system using RFID technologies for shop-floor management. Several relevant real-time manufacturing data capturing cases have been illustrated in RFID-enabled fixedposition assembly (Huang et al. 2007), wireless production line (Huang et al. 2008a), wireless shop-floor inventory management (Huang et al. 2008b) and all-in-one smart gateway (Zhang et al. 2010b). More recently, Zhang et al. (2010c) present an agent-based workflow management framework for RFID-enabled real-time reconfigurable manufacturing.

\section{Overall infrastructure of RTMITI}

The aim of the research reported here is to apply RFID technologies and develop a real-time manufacturing information tracking infrastructure (RTMITI) for extended enterprises to implement real-time visibility and interoperability during manufacturing execution. Figure 1 shows the overall architecture of RFID-enabled RTMITI of extended enterprises. Four core components are involved in this infrastructure to

\footnotetext{
${ }^{1}$ http://www.productivitybyrfid.com/.
}

implement manufacturing information tracking in extended enterprises. They are described as follows.

RFID-enabled manufacturing data capturing

Manufacturing information capturing plays a very important role in the proposed infrastructure. This component is responsible for capturing the real-time manufacturing information occurred at different manufacturing resources. Here, RFID technologies are adopted to capture real-time manufacturing information. The key issues in this component are (1) how to configure the RFID devices including RFID readers and tags to traditional manufacturing resources such as employees, machines and materials so that the real-time manufacturing data can be captured from the device level; and (2) how to design a workflow among manufacturing resources such as employees, machines and materials equipped with RFID devices to track each operation information during manufacturing execution.

\section{Information management center}

Information management center is mainly for the unified data management (e.g. EPC, CAPP, Extended Enterprises etc.) of the whole extended enterprise, and provide facilities for the tracking system to communicate with enterprise servers or 
applications. The information management center is mainly composed of the following three modules:

Real-time manufacturing Database is responsible for providing physical storage for the historical data from real-time manufacturing data captured by RFID devices and real-time manufacturing process information from statistical calculating methods.

Registry stores all the definition data, e.g. the relative information between RFID readers and manufacturing resources, the relative information between EPC data of tags and manufacturing resources etc. Repository stores the dynamical RFID events and corresponding data occurred at each RFID device.

Data source service aims to build up a bridge for information communication between heterogeneous enterprise information systems. It is developed to (i) communicate with enterprise servers or applications including MES, ERP, SCM, and legacy systems; (ii) retrieve enterprise data from enterprise servers or applications; and (iii) organize real-time production data in different views and transmit them to enterprises services or applications.

\section{Real-time manufacturing information processing model}

The real-time manufacturing data captured by RFID devices is unorderly and meaningless for extended enterprises. Although these data record the real status of manufacturing execution, they still need to be processed to provide meaningful information such as overall manufacturing cost, manufacturing progress, WIP inventory etc. for extended enterprise. This component is responsible for designing and developing the corresponding model and methods to provide real-time statistical information for extended enterprises based on realtime manufacturing data captured by RFID devices.

Multi-view based real-time manufacturing information explorers

Multi-view based real-time manufacturing explorers for extended enterprises during manufacturing execution are provided for target users to visualize real-time manufacturing information so as to support their appropriate manufacturing operations and facilitate adaptive decision making.

According to the hierarchy of extended enterprises, the real-time manufacturing explorers can be divided into multilevel. It can track the real-time manufacturing information of extended enterprise, enterprise, shop floor, production line, as well as individual equipment etc. This component aims to display the real-time manufacturing information of WIP items based on the captured real-time data from each manufacturing resource using smart device. For example, the real-time information such as total production demand and finished, current task in process, number of Scraps, wellness of each workstation etc. can be dynamically displayed.

In this paper, we focus mainly on two of these core components, namely RFID-enabled real-time manufacturing capturing and real-time data processing methods.

\section{RFID-enabled real-time manufacturing information capturing in shop floor}

Manufacturing information capturing solution

To track the real-time operations involved in manufacturing activities, one of the most important things is to make each operation, both manufacturing operation and logistics operation, become "information transparent" and "digital". This means that related operators in any location can know what is happening during the operation execution.

Generally, extended enterprises structure is formed according to a product BOM (Bill of Materials) (Zhang et al. 2010d). It is necessary to deploy RFID devices to each shop floor involved so that the real-time manufacturing information can be captured for whole extended enterprises. Figure 2 shows the RFID-enabled real-time manufacturing information tracking model for capturing the real-time information of each operation at corresponding machining equipments involved in extended enterprises.

\section{Deployment of RFID-enabled shop-floor}

In order to capture the real-time manufacturing information of manufacturing operations, it is necessary to identify shopfloor objects to which RFID tags and/or readers are attached. RFID readers and tags are deployed in several ways.

- Each equipment of the shop floor is equipped with one RFID reader. This reader is multi-functional and is responsible for reading the tags attached to different objects.

- Readers are also available at the shop floor storeroom for the tools and materials, and in management points (e.g. shop floor entrances).

- Staff members have their staff cards which can be read and written by the RFID readers.

- Critical tools are also attached with RFID tags. They are considered critical and therefore deserve tags due to their important roles and conditions in the assembly process.

- One of the components in the product assembly is considered critical and each critical component is attached with an RFID tag. This tag, as a mobile memory of the "smart" WIP products, plays important roles throughout the assembly process and even retained for subsequent supply chain applications. 
Fig. 2 Configuration of RFID devices in extended enterprises for capturing real-time manufacturing information

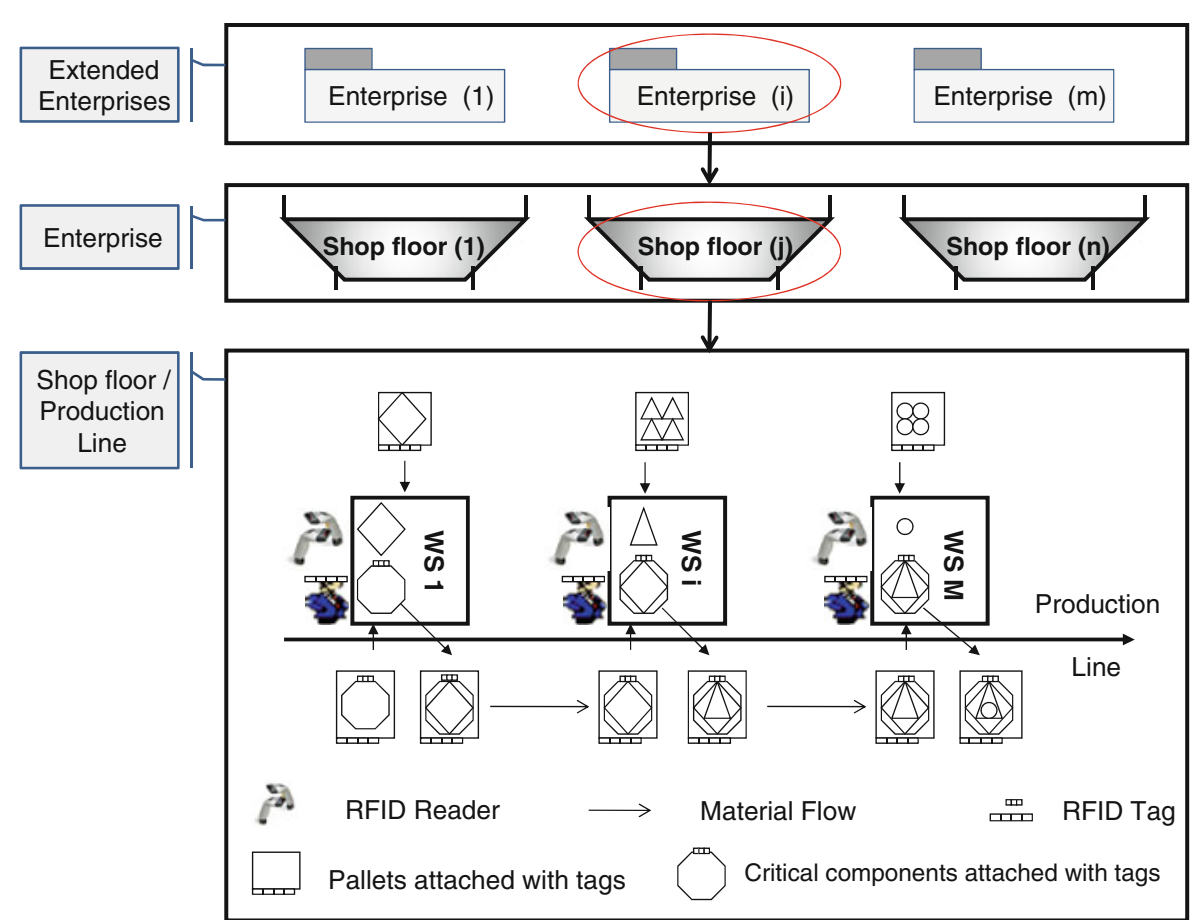

- RFID tags are also attached to all the pallets for holding WIP materials, including components/parts, scraped materials, and semi-finished subassemblies and finished product assemblies.

It is stated that each shop floor has a server computer to which the reader is connected. This server is also used to manage the RFID readers. These tags are not only used for tracking the flow of materials but also for controlling the WIP inventories. Such field information will in turn be fed back and used for production planning and scheduling.

RFID-event-driven real-time manufacturing information flows

Having deployed RFID devices across the shop-floor, the next requirement is how RFID readers and tags interact and communicate with each other to implement the RFID-eventdriven information flows.

For better understanding, we will introduce the main operations of manufacturing execution. In real manufacturing environment, a manufacturing activity can be regarded as a series of relevant operations to finish a basic task. The involved operations are carried out according to specific logical sequence. Figure 3 shows an assembly manufacturing activity consists of six operations, namely (1) check a manufacturing job, (2) check materials, (3) assembly, (4) finish one WIP, (5) repeat assembly and (6) finish job.

To sum up how the tagged manufacturing resources work together and the RFID-event-driven information flows, Fig. 3 illustrates the collaborative workflow of the manufacturing activity.

At the beginning of each shift an operator reports on duty using his/her staff card at the entrance of equipment. This operator is prompted by the reporting or inquiry screen about his/her designated machine and tasks within this shift.

Next, the operator finds the correct machine again using the staff card for verification. If the machine is correct, work details are provided (downloaded) from the backend application systems to the desktop computer of this operator.

Then, the "check information" will prompt the operator to check the status of the critical tools and WIP materials needed for the assembly operations at this workstation. Instructions are given to the operator in order to collect the right (amount) tools and materials. Outstanding tools and materials are collected from the workshop Tools and Stores Room using the staff card. Because critical tools and pallets of WIP materials are equipped with RFID tags, they can be checked in at the workstation. Their arrival at the workstation is also verified against the assembly plan and schedule from the APS explorers.

Once everything is checked in "ready" status, the assembly operations at this machine can start. During the manufacturing process seen in Fig. 3, a sub-assembly is taken into the workspace of the machine. This movement is tracked by one of the antennas of the RFID reader because the critical component previously included in this subassembly is now equipped with an RFID tag. Two other components are brought into the workspace. Their movement is not tracked because they do not have any RFID tags with them. Instead, 
Fig. 3 An example of a manufacturing activity: assembly

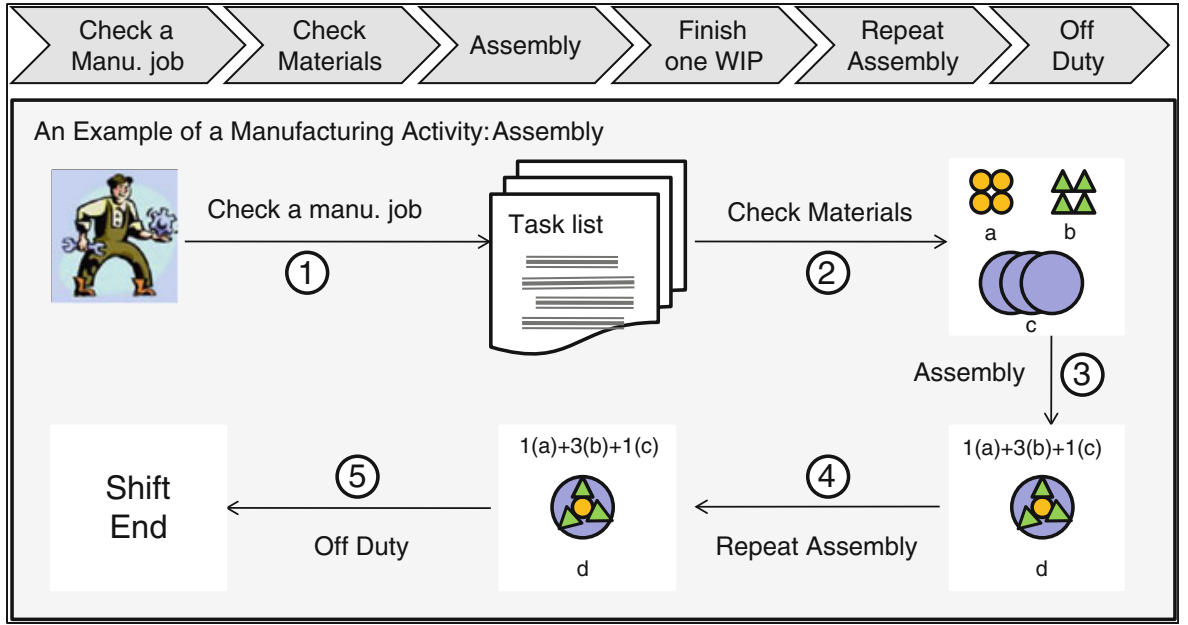

such movement is indirectly deduced and monitored through the check-in and check-out of the critical component (the subassembly, actually) through the backend application systems. If the inventory of any of these materials is below the safety level, a signal is prompted to the corresponding personnel in the appropriate sections.

The above activities repeat until all of the production volume allocated to this machine and operator is accomplished. At any stage, the real-time manufacturing information captured by RFID devices will be also stored in repository.

\section{Real-time manufacturing information processing methods for extended enterprises}

Information propagation model in extended enterprises

For describing the mechanism of manufacturing information tracking in extended enterprises, we will briefly introduce the mechanism of forming extended enterprises. A product tree model (Jiang and Chen 2007) is used to build the relationship between extended enterprises and corresponding product. In this mechanism, the core is to decompose the different parts/assemblies into three types, that is, in-house, out-house, and outsourcing part/assemblies, according to the correspondent product $\mathrm{BOM}$ and the own needs of a specific enterprise. Then, an extended enterprise can be formed according to the three types of product BOM. The organizational structure of extended enterprises can be seen as a core enterprise (root node) plus co-enterprises (branch nodes or leaf nodes) that distribute in different levels of the tree. Here, the parts/assemblies that allocate to a co-enterprise concerning branch node can be decomposed further into the above three types. The parts/assemblies that allocate to a co-enterprise concerning leaf node are indecomposable. This kind of co-enterprise is either a manufacturer or supplier. In fact, the decomposition of parts/assemblies depends on a specific enterprise. That is, the decomposition is enterprise-related.

Once the enterprise tree is created, a manufacturing execution sub-system that is correlated with a co-enterprise and is used for finishing the correspondent manufacturing operations of in-house parts/assemblies can be configured by means of assigning suitable manufacturing activities directly to suitable shop floors and digitalized machining equipments. Here, a shop floor consists of one or several manufacturing cells and a manufacturing cell is composed of several machining equipments. As shown in Fig. 4, such an assignment is illustrated and a process planning and scheduling integrated tool is used to support the correspondent information processing. In this way, a dynamic layout that consists of selected shop floors and machining equipments shows the feature of the manufacturing execution sub-system. For the manufacturing execution system of the extended enterprises created, it can be formed in terms of summarizing all the manufacturing execution sub-systems that belong to different co-enterprises and core enterprise.

Real-time manufacturing information processing

During manufacturing execution in extended enterprises, the real-time progress and the manufacturing cost of production tasks will provide management level the accurate and timely information for making optimal and vital decision. This section will describe how to deal with the distributed real-time data captured by RFID devices to form meaningful and useful manufacturing information for extended enterprises.

\section{Real-time WIP progress tracking}

This kind of information reflects the real-time manufacturing progress of a process, part, assembly or product. Realtime progress provides an important basis for shop-floor and 
Fig. 4 Information propagation model of extended enterprises
Fig. 5 Real-time manufacturing information processing model

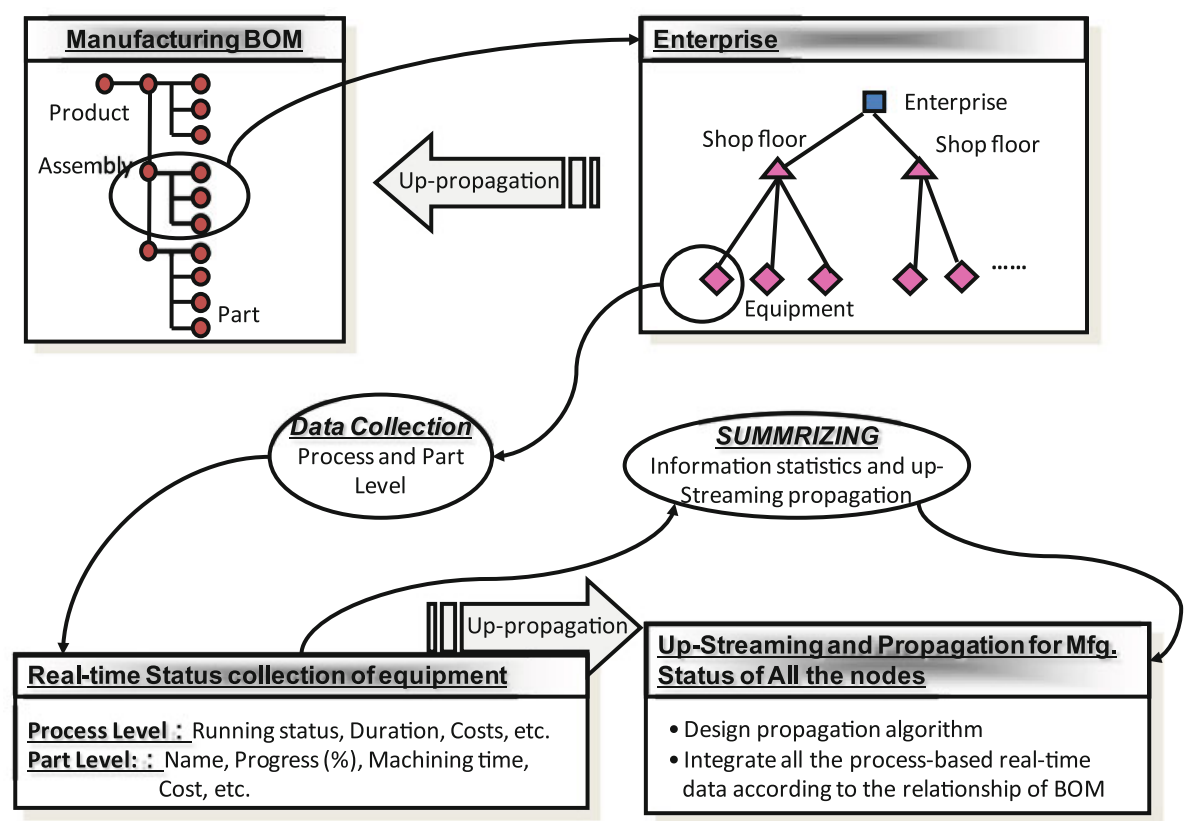

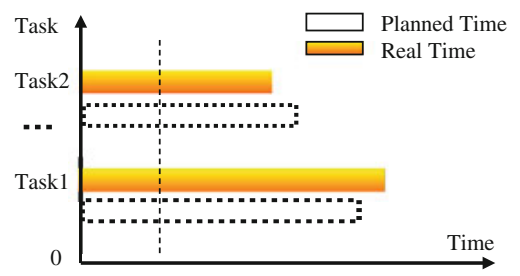

(a) The Progress of Task (Process Level)

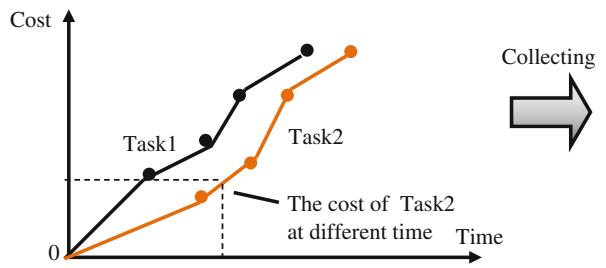

(C) The Cost-Time Curve of Task (Part Level)

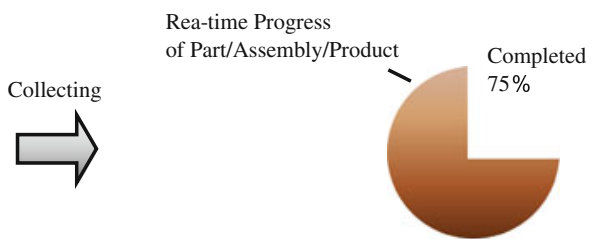

(b)

The Statistical Progress Information of Part / Assembly /Product Level

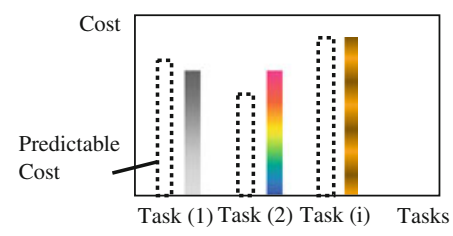

(d) The Statistical Cost of Task
(Assembly / Product) enterprise decision. For example, production scheduling can be conducted based on real-time production progress of ongoing tasks and work-in-progress (WIP) inventory status.

As shown in Fig. 5a, real-time progress of a manufacturing process, $\mathrm{RPT}_{\text {process }}$, could be simply calculated as follows:

$\mathrm{RPT}_{\text {process }}=\frac{\mathrm{RT}_{\text {process }}}{\mathrm{PT}_{\text {process }}} \times 100 \%$

$\mathrm{RT}_{\text {process }}$ means the real-time production time of this process, while $\mathrm{PT}_{\text {process }}$ is the planned production time.

Based on $\mathrm{RPT}_{\text {process }}$, the real-time progress of parts, assemblies and products can all be calculated according to the BOM relationships. The formula below is used to calculate $\mathrm{RPT}_{\text {product }}$, i.e. the real-time progress of product.
$\mathrm{RPT}_{\text {product }}=\frac{\sum_{i=1}^{r} \sum_{j=1}^{n} \sum_{k=1}^{m} \mathrm{RT}_{\text {process }[i, j, k]}}{\sum_{i=1}^{r} \sum_{j=1}^{n} \sum_{k=1}^{m} \mathrm{PT}_{\text {process }[i, j, k]}} \times 100 \%$

$\mathrm{RT}_{\text {process }[i, j, k]}$ is the real production time of the process $(k)$ of part $(j)$ of assembly $(i)$ of the "product". $\sum_{i=1}^{r} \sum_{j=1}^{n} \sum_{k=1}^{m} \mathrm{RT}_{\text {process }[i, j, k]}$ is the real production time of the "product", while $\sum_{i=1}^{r} \sum_{j=1}^{n} \sum_{k=1}^{m} \mathrm{PT}_{\text {process }[i, j, k]}$ is the planned production time of the "product". Figure $5 \mathrm{~b}$ shows the graphic expression of the real-time progress of assembly and product by using Java 2D.

\section{Real-time production cost tracking}

This kind of information is used to trace the production cost of a manufacturing process. Cost information of a 
manufacturing process serves as the important basic data source for tracing the production cost of part, assembly and product. The cost of a "process" cost can be calculated as follows:

$\mathrm{CT}_{\text {process }}=T_{\text {process }} \times C_{\text {equip }}$

$\mathrm{CT}_{\text {process }}$ means the production cost of a "process" at time $T_{\text {process }}$, which stands for the currently expensed time of this process. $C_{\text {equip }}$ represents the machining cost rate in the corresponding equipment.

Based on the cost of processes, the production cost of a part can be easily calculated as follows.

$\mathrm{CT}_{\text {part }}=\sum_{i=1}^{n} T_{\text {process }[i]} C_{\text {equip }[i]}$

As can be seen, such a cost calculation is to summarize the costs of all the "processes" related to this specific part. $\mathrm{CT}_{\text {part }}$ means the real-time production cost of the part, $n$ represents the total number of "processes", $T_{\text {process }[i]}$ expresses the expensed time of the process $[i]$, and $C_{\text {equip }[i]}$ denotes the machining price per hour in the corresponding machining equipment. An example of part cost is shown in Fig. 5c. In the same way, costs for assembly or product can also be calculated, and examples are shown in Fig. 5 d.

\section{Case study}

Following the concepts and methodologies described in the preceding sections, a demonstration system for tracking realtime manufacturing information of extended enterprises is developed. As seen in Fig. 6, the left of the figure shows the physical hierarchy of extended enterprises, namely manufacturing equipments, shop floors, enterprises and extended enterprises. The right of the figure illustrates the real-time manufacturing information of different manufacturing sites. Such a real-time manufacturing tracking system in extended enterprises could be briefly described as follows:

(1) For each manufacturing process, the operations could be timely captured by the RFID devices installed at equipments. This real-time information can be used to calculate the process based real-time manufacturing information such as cost-time curve, WIP inventory and manufacturing status etc, seen in the bottom of Fig. 6.

(2) Based on the real-time process manufacturing information, the real-time manufacturing information of each part or assembly of each shop-floor/enterprise could be calculated through up-propagating the information of relative equipments, seen in the middle of Fig. 6.

(3) In the same way, the overall real-time manufacturing information of extended enterprises, such as manufacturing cost, manufacturing progress and detailed WIP information can be timely tracked and displayed, seen in the top of Fig. 6.

\section{Conclusion}

Recent developments in RFID and Auto-ID technologies have created opportunities for developing advanced manufacturing information systems with real-time traceability, visibility and interoperability. In extended enterprises, realtime WIP tracing and tracking enable the production manger

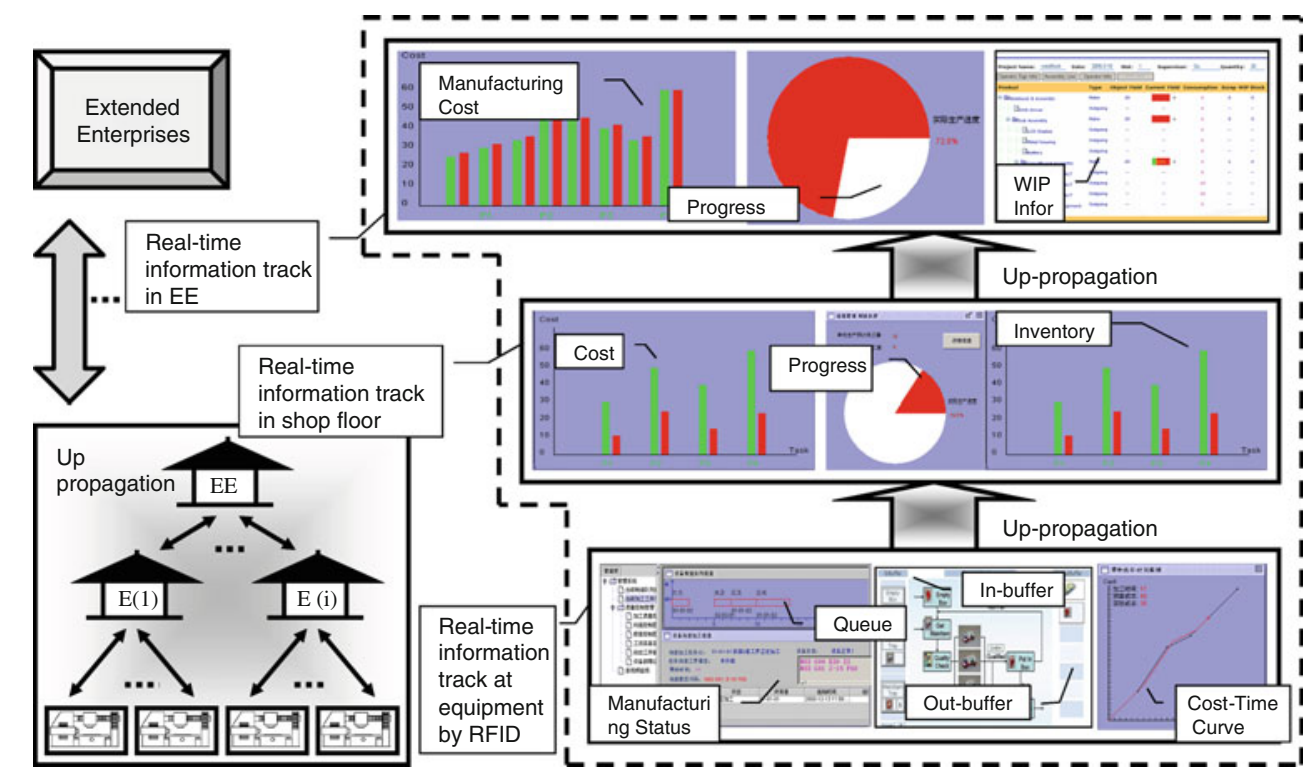

Fig. 6 RFID-enabled real-time manufacturing information tracking in extended enterprises 
to improve the efficiency and effectiveness of production supervision and decision and largely reduce the production disturbances.

In this paper, key issues on how to track the real-time manufacturing information for extended enterprises are discussed and developed. The contributions of this paper could be summarized as follows:

(1) An overall infrastructure of RFID-enabled real-time manufacturing information for extended enterprises is proposed and discussed, which provides model and methods for configuring RFID devices at manufacturing resources, capturing real-time manufacturing information and tracking and processing the real-time manufacturing information.

(2) A configuration method of attached RFID readers and tags to corresponding manufacturing resources is presented and designed to capture the real-time manufacturing information occurred at manufacturing resources sides.

(3) Based on the real-time manufacturing information captured by RFID devices, corresponding treatment methods such as manufacturing cost, manufacturing progress, WIP inventory etc. are established. Moreover, statistical model and methods are built to track the real-time manufacturing information throughout the extended enterprises.

The above infrastructure and methods just provide a kind of useful framework and mechanism to make the manufacturing information of extended enterprises be real-time visible, traceable and transparent. The meaningful real-time manufacturing information will support different management level of extended enterprises to make accurate decision. Future research works would focus on the quality data capturing and real-time diagnostic methods of manufacturing processing. In addition, up-level decision such as re-scheduling and JIT (Just-in-time) production based on real-time shop-floor WIP information should be taken into account for optimal management and control in extended enterprises environment.

Acknowledgments Authors would like to acknowledge financial supports of National Science Foundation of China (50805116), Hi-Tech 863 (2009AA04Z147) and HKSAR ITF (GHP/042/07LP). This paper has been presented in DET2009 conference held at the University of Hong Kong during 14-16 December 2009 and included in the conference proceeding published by Springer.

Open Access This article is distributed under the terms of the Creative Commons Attribution Noncommercial License which permits any noncommercial use, distribution, and reproduction in any medium, provided the original author(s) and source are credited.

\section{References}

Amours, S., Montreuil, B., Lefrancois, P., \& Soumis, F. (1999). Networked manufacturing: The impact of information sharing. International Journal of Production Economics, 58(1), 63-79.

Chan, M., \& Chung, W. (2002). A framework to develop an enterprise information portal for contract manufacturing. International Journal of Production Economics, 75(1-2), 113-126.

Chen, Y. M., \& Jan, Y. D. (2000). Enabling allied concurrent engineering through distributed engineering information management. Journal of Robotics \& Computer Integrated Manufacturing, 16(1), 9-27.

Estrem, W. A. (2003). An evaluation framework for deploying Web Services in the next generation manufacturing enterprise. Journal of Robotics and Computer Integrated Manufacturing, 19(1), 509-519.

Huang, G. Q., Zhang, Y. F., \& Jiang, P. (2007). RFID-based wireless manufacturing for walking-worker assembly shops with fixedposition layouts. International Journal of Robotics and Computer Integrated Manufacturing, 23(4), 469-477.

Huang, G. Q., Zhang, Y. F., \& Newman, S. (2008a). RFID-enabled real-time wireless manufacturing for adaptive assembly planning and control. Journal of Intelligent Manufacturing, 19(6), 701-713.

Huang, G. Q., Zhang, Y. F., \& Jiang, P. Y. (2008b). RFID-based wireless manufacturing for real-time management of job shop WIP inventories. International Journal of Advanced Manufacturing Technology, 36, 752-764.

Iskanius, P., \& Alaruikka, A. M. (2007). Streamlining information flow in steel product design and manufacturing industry network. International Journal of Integrated Supply Management, 3(3), 244-260.

Jagdev, J. (1998). The extended enterprise: A context for manufacturing. Production Planning \& Control, 9(3), 216-229.

Jiang, P., \& Chen, B. (2007). Some key issues on enabling e-manufacturing as a part of product-driven e-business process via e-service. International Journal of Manufacturing Technology and Management, 10(4), 380-399.

Johnson, D. (2002). RFID tags improve tracking, quality on Ford line in Mexico. Control Engineering, 49(11), 16-16.

Kohn, W., Brayman, V., \& Littleton, J. (2005). Repair-control of enterprise systems using RFID sensory data. IIE Transactions, 37(4), 281-290.

Krishnamurthy, S., \& Zeid, I. (2004). Distributed and intelligent information access in manufacturing enterprises through mobile devices. Journal of Intelligent Manufacturing, 15(2), 175-186.

Li, Z., Gadh, R., \& Prabhu, B. S. (2004). Applications of RFID technology and smart parts in HS manufacturing. In Proceedings of DETC'04: ASME 2004 design engineering technical conferences and computers and information in engineering conference, September 28-October 2, 2004, Salt Lake City, Utah USA.

Omar, L. O., \& Moramay, R. H. (2007). A formal framework to integrate express data models in an extended enterprise context. International Journal of Intelligent Manufacturing, 18(3), 371-381.

Rupp, T. M., \& Ristic, M. (2004). Determination and exchange of supply information for co-operation in complex production networks. Robotics and Autonomous Systems, 49(3-4), 181-191.

Sun, H. B., \& Jiang, P. Y. (2007). Study on manufacturing information sharing and tracking for extended enterprises. International Journal of Advanced Manufacturing Technology, 34, 790-798.

Udoka, S. J. (1992). The role of automatic identification (Auto ID) in the computer integrated manufacturing (CIM) architecture. Computers and Industrial Engineering, 23(1-4), 1-5. 
Zhang, Y. F., Jiang, P. Y., \& Huang, G. Q. (2008). RFID-based smart kanbans for just-in-time manufacturing. International Journal of Materials and Product Technology, 33(1-2), 170-184.

Zhang, Y. F., Huang, G. Q., Qu, T., Ho, O., \& Sun, S. (2010a). Agent-based smart objects management system for ubiquitous manufacturing. International Journal of Robotics and Computer Integrated Manufacturing. doi:10.1016/j.rcim.2010.09.009.

Zhang, Y. F., Huang, G. Q., Qu, T., \& Ho, O. (2010b). Agent-based workflow management for RFID-enabled real-time reconfigurable manufacturing. International Journal of Computer Integrated Manufacturing, 23(2), 101-112.
Zhang, Y. F., Qu, T., Huang, G. Q., \& Ho, O. (2010c). Agent-based smart gateway for RFID-enabled real-time wireless manufacturing. International Journal of Production Research (in press).

Zhang, Y. F., Jiang, P. Y., Huang, G. Q., Qu, T., \& Hong, J. (2010d). Task-driven e-manufacturing resource configurable model. International Journal of Intelligent Manufacturing. doi:10.1007/s10845-010-0470-8.

Zhang, S., Shen, W., \& Ghenniwa, H. (2004). A review of Internetbased product information sharing and visualization. Computers in Industry, 54(1), 1-15. 